\title{
Fórmulas de despedida de matiz religioso en las cartas del siglo XVII
}

\section{Religious References in Farewell Expressions in Seventeenth-Century Correspondence}

Zaida Vila CArneiro [zaida.vila@unirioja.es]

Universidad de La Rioja, España

Fátima FAya Cerqueiro [fatima.faya@uclm.es]

Universidad de Castilla-La Mancha, España

\begin{abstract}
RESUMEN
Este trabajo analiza la expresión del acto de habla de las despedidas en colecciones de cartas españolas del siglo XVII. Se tiene en consideración correspondencia de variado espectro, incluyendo textos auténticos de carácter mercantil, íntimo y diplomático, junto con misivas insertadas en piezas teatrales. El análisis contempla todas las expresiones de carácter religioso que se solían utilizar pidiendo la intervención divina para conservar la salud del destinatario, de modo que permite establecer el grado de convencionalización que tenían las despedidas epistolares y los factores que intervenían en el uso de las distintas fórmulas, como el rango social de emisor y receptor.
\end{abstract}

\section{Palabras Clave}

despedidas; Siglo de Oro; correspondencia; cortesía

\begin{abstract}
This study analyses how the speech act of farewells is expressed in seventeenth-century Spanish letters. Different types of correspondence are considered, including authentic material, namely commercial, intimate and diplomatic letters; and constructed letters that are part of drama plays. The analysis takes into account all the religious expressions that were used as well-wishing formulae imploring divine intervention. Thus, it is possible to establish the degree of conventionalisation of valedictions and the different factors affecting the use of the different formulae, such as the social rank of both sender and receiver.
\end{abstract}

\section{KEYWORDS}

farewells; Golden Age theatre; correspondence; politeness

RECIBIDO 2016-09-30; ACEPTADO 2016-12-30 


\section{Introducción}

El siguiente estudio parte de un trabajo anterior en el que se analizaba la fórmula de despedida a Dios en el teatro del Siglo de Oro (Vila y Faya 2016). En dicho trabajo, se detallaban una serie de expresiones que funcionaban como fórmulas de despedida fijadas con referencias explícitas a Dios. De este modo, se ponía de relieve el uso de expresiones como Dios te guarde y similares como respuesta a una despedida previa del tipo a Dios en pares de adyacencia que mostraban un alto grado de convencionalización y que hacían prever que la forma a Dios / adiós no había completado aún su proceso de gramaticalización.

El objetivo principal del presente estudio consiste en analizar las expresiones de despedida fijadas en el género epistolar del siglo XVII, con especial énfasis en los referentes de carácter religioso y en las posibles diferencias en el grado de fijación en varios corpus de cartas de distinta índole, para confirmar la existencia o no de la elección de fórmulas de despedida distintas en el discurso hablado frente al escrito y proporcionar información detallada sobre el repertorio de estructuras disponibles en esa época.

\section{Fórmula de despedida a Dios en el Siglo de Oro}

Briz y Albelda (2010) entienden el acto de habla de despedidas como parte de la denominada "cortesía normativa", por su carácter social en las relaciones interpersonales, ya que sirven para poner fin a una conversación teniendo en cuenta las convenciones de dicha sociedad. Como indica Jucker (2010: 232), los saludos y las despedidas presentan rasgos muy variados dentro de una misma lengua y periodo histórico, pues pueden limitarse tan solo a una expresión formulaica o constituir un acto de habla más elaborado y creativo y pueden carecer de significado proposicional o conllevar más funciones sociales.

Las despedidas se clasifican dentro de los actos de habla expresivos (ver Searle 1979: 29) y suelen tener una estructura fijada. Así, en español contemporáneo es habitual excusarse al finalizar la conversación (ver Álvarez 2005: 61-63; Slowik 2009: 73-74; Fernández 2010: 116). Dichas expresiones funcionarían como atenuante para que la despedida cumpla con determinadas condiciones de fortuna - felicity conditions - (Austin 1962: 11-15) que la hagan posible. Fernández (2010: 113-114) analiza distintas secuencias de cierre en conversaciones telefónicas en las que hay elementos fijados como pre-cierre; aceptación del ofrecimiento de cierre; despedida y despedida y cierre. Las partes de pre-cierre y aceptación suponen que los interlocutores tienen en consideración la imagen del otro cuando negocian la despedida. Sin embargo, estas funciones sociales no están presentes en el género epistolar, ya que las convenciones de este tipo de texto permiten que el autor se pueda despedir sin necesidad de justificación de carácter temporal o sin extender la anticipación más allá del propio párrafo de despedida.

Haverkate (1994: 87) indica que "las fórmulas de saludo y despedida [...] en no pocos casos, revelan alusiones a la religión, la cultura o la sociedad.” Así, entre las expresiones en despedidas en español contemporáneo que recoge Álvarez muchas incluyen Dios en su formulación, de este modo, junto con adiós, encontramos otras como Ande con Dios, Vaya [usted] con Dios, Quedad con Dios, Con Dios (con elipsis), Hasta mañana si Dios quiere, A la paz de Dios y Dios os / te guarde 
(Álvarez 2005: 62). De forma similar, Morant (1991: 61-62) señala el origen de adiós, fórmula de despedida más común entre las citadas, como elipsis de a Dios seas o quede usted con Dios. En La Celestina se han analizado las bendiciones como acto ilocutivo con función de despedida o saludo, incluyendo algunas como Quede Dios contigo y Adiós te quedes (cf. García 2004: 376). Por tanto, la referencia a Dios en el acto de habla de despedidas podría estar relacionada con el uso de bendiciones en la misma función discursiva. Algunos autores también han mostrado la evolución de bendiciones usadas con valor de despedida hacia expresiones sin connotación religiosa evidente en la historia del inglés (cf. Arnovick 1999; Grzega 2005; Jucker 2010), como en la más reconocida forma goodbye que se habría originado en God be with you.

Un estudio previo sobre el origen de adiós y su uso como fórmula de despedida en el teatro español del Siglo de Oro mostraba que un grupo de ejemplos del tipo Dios os guarde con valor de despedida no formaban parte de un par de adyacencia, sino que se ubicaban en las últimas líneas de epístolas incluidas en las comedias calderonianas (Vila y Faya 2016). Este hecho propició el interés por averiguar si dicha expresión tenía un carácter formulaico y qué otras expresiones con un sentido religioso se usaban con una función pragmática similar en la correspondencia del Siglo de Oro.

En este artículo nos proponemos demostrar que la formulación de despedida en el Siglo de Oro cambia cuando el formato varía de diálogo-conversación a otros géneros como el epistolar, en el cual la respuesta no es de carácter inmediato.

\section{Descripción del corpus}

El corpus que tomaremos como base para este estudio consta de una serie de documentos relevantes de la época como son las Cinco Cartas Político-Literarias de D. Diego Sarmiento de Acuña. Primer Conde de Gondomar. Embajador a la Corte de Inglaterra. 1613-22, la Correspondencia mercantil en el siglo XVII: las cartas del mercader Felipe Moscoso (1660-1685) y las Cartas de sor María de Ágreda y del rey don Felipe IV. Asimismo, se examinará el corpus empleado en Vila y Faya (2016), en particular, las cartas en prosa que aparecen en las 72 piezas teatrales incluidas en las seis primeras partes de comedias de Calderón de la Barca, publicadas en 1636, 1637, 1664, 1672,1682 y 1683 , respectivamente ${ }^{1}$.

\subsection{Género epistolar}

Aunque el género epistolar no aparece recogido en clasificaciones de diálogos como la de Culpeper y Kytö (2010), este tipo de texto proporciona información muy valiosa a nivel lingüístico, ya que las cartas como eventos comunicativos asumen un escritor y un destinatario sin la intervención de un narrador. Fitzmaurice (2000: 361-364), por ejemplo, defiende el carácter interactivo e interpersonal de las cartas a pesar de su forma escrita. Precisamente por ser textos no orales,

1 En el Siglo de Oro las comedias solían ser editadas en unos tomos que contenían, cada uno, doce obras. Estos volúmenes eran las denominadas partes. 
a las cartas privadas no se les pueden aplicar algunos de los parámetros que sugiere Koch (1999) como indicadores de la inmediatez comunicativa, carecen así de inmediatez física o espontaneidad, aunque sí aparecen otros, como el nivel de privacidad, la familiaridad o elementos deícticos compartidos entre autor y receptor. Se podría cuestionar si son o no un texto de tipo dialógico, ya que, como indica Jucker (2000:23), una carta puede reaccionar a una carta anterior o anticipar las reacciones del lector aunque la respuesta no sea inmediata. Por tanto, las epístolas incluyen elementos de carácter monológico y dialógico y el propio Jucker las incluye como un tipo de diálogo de datos escritos auténticos (1998: 5).

Las características mencionadas hacen que este tipo de texto sea muy adecuado en el estudio de la pragmática ya que suelen incluir rasgos lingüísticos cercanos a la lengua oral. Además, como afirma Palander-Collin (2010: 661), las cartas suelen añadir una mayor cantidad de información contextual que muchos otros tipos de texto, por lo que resultan una base idónea cuando se requiere cierta contextualización para interpretar el uso del lenguaje. El género epistolar se muestra especialmente valioso para el estudio de fenómenos lingüísticos específicos que requieren interacción, como los saludos o las fórmulas de cortesía (Jucker 1994: 535). Las cartas también resultan de gran interés para el estudio de los actos de habla, puesto que es muy probable encontrar peticiones, disculpas, agradecimientos, promesas, etc. (Jucker 1994: 535). Por consiguiente, las cartas de carácter privado de periodos anteriores pueden proporcionar datos relevantes y fehacientes sobre muchos aspectos pragmáticos, y sobre todo aquellas que incluyan elementos de tipo formulaico y de cortesía.

\subsection{Corpus}

A la hora de seleccionar el corpus para nuestro estudio, tuvimos en cuenta la necesidad de que este fuese de tipología variada y que abarcase prácticamente todo el siglo XVII. Así, contamos en este trabajo con correspondencia de carácter diplomático, mercantil, íntimo y literario, escrita desde 1606 a 1685.

En cuanto a las epístolas de corte diplomático, hemos seleccionado la edición decimonónica de las Cinco Cartas Político-Literarias de D. Diego Sarmiento de Acuña, la cual recoge parte de la correspondencia del erudito conde de Gondomar, embajador de España en Londres de 1613 a 1622 y pieza clave en las relaciones angloespañolas del momento. Se trata de extensas misivas de principios del siglo XVII dirigidas a importantes personalidades de la época.

Por otro lado, en la Correspondencia mercantil en el siglo XVII: las cartas del mercader Felipe Moscoso (1660-1685), recopilada y editada por Vicente Montojo, las misivas tienen como protagonista a Felipe Moscoso, comerciante oraní converso de gran importancia en la época ${ }^{2}$.Este subcorpus está compuesto por 789 cartas, 325 epístolas recibidas de personas de distinta procedencia (Levante, Andalucía, Madrid, Portugal, Italia...) y 464 enviadas, escritas todas ellas entre los años 1660 y 1685. En esta correspondencia hay cartas redactadas por mujeres, si bien la inmensa mayoría proviene de la mano de un hombre. En algunas ocasiones, la relación entre emisor y receptor

2 Para saber más acerca de su persona, puede consultarse la introducción de la obra en donde se da cuenta de sus orígenes, sus creencias religiosas, su éxito social, su labor mercantil, etc. 
es familiar, como es el caso de Manuel Moscoso, hermano de Felipe Moscoso. La correspondencia con muchos de los destinatarios y/o remitentes es habitual, superando la veintena de cartas en algunos casos, con un alto grado de interacción y referencias a cartas previas. Además, en muchas ocasiones se revela una relación de carácter más personal, con alusiones frecuentes a la amistad entre remitente y destinatario ${ }^{3}$.

En lo que concierne a las misivas pertenecientes a la esfera de lo íntimo, hemos seleccionado las Cartas de sor María de Ágreda y del rey don Felipe IV ${ }^{4}$, las cuales han sido recogidas en dos tomos, aunque debido al volumen del corpus empleado y por ser suficientemente significativo, analizaremos solo el primero de ellos. Este intercambio epistolar destaca por la conservación de un gran número de misivas entre ambos y, sobre todo, por el agrupamiento de la colección, como indica Castillo Gómez (2014: 148), frente a las epístolas de otras religiosas como Teresa de Jesús. Esto se debió a la voluntad del monarca de conservarlas encuadernadas por el valor espiritual que les otorgaba. Recordemos que sor María de Ágreda fue consejera espiritual del rey Felipe IV y la correspondencia entre ambos se mantuvo desde 1643 hasta el año de la muerte de la religiosa en 1665. De las 614 cartas que se conservaron, se incluyen 234 en el primer volumen, hasta $1649^{5}$. El soberano narra a la monja los eventos que van sucediendo y las dificultades en las que se encuentra, buscando en ella una intercesora con Dios para que le ayude a solventar o sobrellevar situaciones adversas, fuesen de índole más personal, como las muertes de su primera esposa o de su hijo el príncipe Baltasar Carlos, o aquellas relacionadas con su faceta de gobierno, como los distintos conflictos territoriales. Sor María atiende las peticiones del rey, asegurándole sus oraciones y proporcionándole consejos de carácter religioso.

Ya, por último, hemos incorporado a este corpus notas, avisos y cartas, en prosa, con emisores y receptores de distinto sexo y estatus social, que aparecen en las seis primeras partes de comedias de Calderón de la Barca. Se trata de un total de 31 escritos breves (no suelen superar las 5 líneas), de los cuales desconocemos, en algunos casos, si son comunicaciones íntegras 6 Aunque es también habitual la reproducción de cartas en verso en el teatro áureo ${ }^{7}$, hemos decidido seleccionar, como ya se ha avanzado, solo aquellas en prosa con el fin de que el corpus global examinado sea homogéneo en lo que respecta a la forma de expresión. Además de ello, como indica Neumeister a propósito de las funciones de la carta en las comedias calderonianas, "La prosa es el medio de información más directo, sin los artificios de la poesía. El dramaturgo pretende de este modo que los sucesos del drama salgan sin deformación de la realidad y sean auténticos" (2011: 278).

3 Sobre el concepto de amistad en la época y su formulación en las cartas, puede verse Marín Cepeda (2016).

4 La edición utilizada para el presente estudio, digitalizada por la Biblioteca Digital de Castilla y León, data de 1885.

5 No se han tenido en cuenta las cartas entre sor María y otros miembros de la Corte, que aparecen en los apéndices.

6 Sí hay ejemplos claros de cartas que no son leídas completamente por el receptor, como en ¿Cuál es mayor perfección, hermosura o discreción? (Comedias V) donde la parte final que se reproduce es "Remitidme poder, noticias y papeles para que yo...”.

7 En Canonica (2015) puede hallarse una estadística aproximada de la proporción de cartas por obra y de la elección entre verso y prosa por parte de dramaturgos como Lope, Tirso y Calderón. 


\section{Análisis de datos}

\subsection{Metodología}

Con el objetivo de identificar todos los referentes de carácter religioso en el cierre de la correspondencia del Siglo de Oro, se ha efectuado una búsqueda exhaustiva en las despedidas de todas las cartas analizadas, valorando tanto la referencia religiosa (Dios, Señor, etc.) como el verbo utilizado, para poder establecer qué expresiones tenían mayor presencia en los distintos tipos de cartas incluidas.

Para llevar a cabo las búsquedas se ha tenido en cuenta la heterogeneidad del material estudiado, por lo que para unificar los criterios de catalogación de estructuras se ha procedido a una búsqueda manual en la parte final de las cartas que permitiese recoger la fórmula de despedida correspondiente y las alusiones de tipo religioso que se incluían. De este modo, en el corpus calderoniano, una vez se han identificado las cartas en prosa incluidas en las comedias, se ha procedido a examinar las últimas líneas de cada texto. La misma metodología se ha adoptado en el corpus de epístolas intercambiadas entre sor María de Agreda y Felipe IV, y los subcorpus de textos mercantiles y diplomáticos, en los que se ha realizado una exhaustiva revisión manual de todas las despedidas.

\subsection{Análisis de datos en los subcorpus}

\subsubsection{Cinco cartas político-literarias de D. Diego Sarmiento de Acuña}

En las cinco cartas de este breve corpus de carácter diplomático se puede establecer una subdivisión en una de las cartas, dirigida al duque de Lerma, al que también se adjunta otra breve carta con el confesor del Príncipe como destinatario, que no incluye despedida, y un dictamen dirigido al monarca Felipe III. Se han recogido seis ejemplos de despedidas, de los cuales cinco incluyen el verbo guardar, como se recoge en la Tabla 1:

\begin{tabular}{|l|c|c|c|c|}
\hline \multirow{2}{*}{} & \multicolumn{4}{|c|}{ Referencias de carácter religioso } \\
\cline { 2 - 5 } & Dios & Dios, nuestro Señor & Nuestro Señor & la Cristiandad \\
\hline TOTAL & $\mathbf{3}$ & $\mathbf{1}$ & $\mathbf{1}$ & $\mathbf{1}$ \\
\hline guardar & 3 & 1 & 1 & - \\
\hline
\end{tabular}

Tabla 1. Referentes y verbos en despedidas (Corpus diplomático)

Se muestran a continuación algunos de los ejemplos que se han extraído de esta colección. En (1) se puede observar una de las expresiones más frecuentes en este y otros corpus, del tipo guarde(me) Dios a vuestra merced, presente en tres de los cinco ejemplos, todos ellos dirigidos a secretarios. Contrasta con esos casos el ejemplo (2), en el que se observa una expresión más elaborada. Aunque se mantienen un referente similar (Dios, nuestro Señor) y el verbo guardar, el 
objeto la vida de vuestra Excelencia revela un trato hacia el duque de Monteleón (que ostenta un título nobiliario de mayor jerarquía que el del conde de Gondomar) mucho más formal y con un elevado tono de cortesía negativa:

(1) Guarde ${ }^{8}$ Dios a v. md., como yo deseo (1613, De Gondomar al secretario Juan de Çiriça, p. 46)

(2) rogando a Dios, nuestro Señor, guarde la vida de vuestra Excelencia, como yo deseo (1617, De Gondomar al duque de Monteleón, p. 97)

El ejemplo (3) forma parte del mencionado dictamen al monarca Felipe III, que Gondomar adjunta en la carta dirigida al duque de Lerma, primer ministro y valido de Felipe III, la despedida se realiza con un mayor grado de sofisticación por el rango social del destinatario:

(3) Vuestra Majestad goce, como la Cristiandad ha menester, y yo, su leal y obediente criado y vasallo, deseo y suplico (1606, De Gondomar a Felipe III, p. 117).

\subsubsection{Correspondencia mercantil en el siglo XVII: las cartas del mercader Felipe Moscoso}

El subcorpus de carácter mercantil es el más numeroso en cuanto al total de cartas incluidas, 789, como ya se ha avanzado. De estas 789 epístolas, solo 29 no incluyen en su parte final menciones de carácter religioso 9 . Esta ausencia podría estar motivada por el hecho de que muchas de ellas constituyen un anexo a cartas inmediatamente anteriores, por lo cual se podría considerar redundante o innecesario el repetir las mismas formulaciones. Asimismo, es preciso señalar que cinco de estas 29 cartas han tenido que ser transcritas con lagunas, por tratarse de documentos rotos o deteriorados.

En lo que respecta al resto de textos, como se muestra en la Tabla 2, la mayor parte de las despedidas hacen uso de guardar como verbo más frecuente, mientras que las referencias de carácter religioso más empleadas corresponden a Dios, seguidas de aquellas con Señor.

\begin{tabular}{|l|c|c|c|c|c|}
\hline & Referencias de carácter religioso & TOTAL & guardar & prosperar & dilatar la vida \\
\hline Dios & $\mathbf{6 7 0}$ & $646^{\mathrm{a}}$ & $3^{\mathrm{b}}$ & 13 \\
\cline { 2 - 6 } & Señor & $\mathbf{7 6}$ & 74 & - & - \\
\cline { 2 - 6 } \\
\cline { 2 - 6 } \\
\end{tabular}

8 Guardar aquí tiene el valor de "Preservar algo del daño que le puede sobrevenir", un significado ya recogido en Autoridades (s.v. guardar).

9 Se trata de los textos C-4, C-5, C-20, C-57, C-58, C-70, C-79, C-80, C-81, C-83, C-111, C-123, C-208, C-243, C-270, C-271, C-273, C-277, C-281, C-287, C-302, A-58, A-76, A-91, A-100, A-110, A-123, A-200 y A-281. 


\begin{tabular}{|l|c|c|c|c|}
\hline Referencias de carácter religioso & TOTAL & guardar & prosperar & dilatar la vida \\
\hline Deo & $\mathbf{1}$ & 1 & - & - \\
\hline cielo & $\mathbf{1}$ & 1 & - & - \\
\hline
\end{tabular}

a Siete de estos ejemplos aparecen combinados con prosperar (3), asistir (2), aliviar (1) y aumentar (1).

b Tres de estos ejemplos aparecen combinados con guardar.

Tabla 2. Referentes y verbos en despedidas (Corpus mercantil)

Por tanto, el tipo de fórmulas más frecuentes en las despedidas corresponden a ejemplos como los que se muestran en (4), (5) o (6), a continuación:

(4) con deseo de que Dios le guarde muchos años (1683, Juan Antonio y Miguel Peragalo a Felipe Moscoso, p. 287)

(5) Vuestra Merced, que Dios guarde, etc. (1663, Felipe Moscoso a Cosme Rodríguez, p. 403)

(6) Nuestro Señor guarde a Vuestra Merced muchos y felices años, etc. (1664, Felipe Moscoso a Carlos Jerónimo, p. 445)

Ejemplos como (5) y (6), que finalizan con “etc.", sugieren que estas expresiones estaban muy convencionalizadas en la correspondencia de la época y sobre todo en la de carácter mercantil. Además, dichos ejemplos guardan cierta similitud con algunos en los que no se llega a incluir una forma verbal, como en (7), por ser innecesario debido a la alta frecuencia de la expresión formulaica, que el receptor identificaría con facilidad:

(7) a Vuestras Mercedes, que Dios, etc. (1663, Felipe Moscoso a Camilo y Antonio de Contreras, p. 410)

En cuanto a la variante de género, no parece haber diferencias en el tipo de estructuras de despedida escritas por mujeres o dirigidas a ellas, como muestran los ejemplos (8) y (9) a continuación, en los que se siguen las convenciones halladas en otras misivas:

(8) guarde Dios a Vuestra Merced muchos años (1674, Marquesa del Viso a Felipe Moscoso, p. 159)

(9) Vuestra Merced, que Dios guarde muchos años (1673, Felipe Moscoso a María Ordóñez, p. 471)

En este corpus también es notable la frecuencia de la expresión "dilatar la vida” en el párrafo de despedida, cuyo significado es similar al de "guardar"10, aunque plasma un mayor grado de cortesía negativa, como en (10):

10 El significado de dilatar era similar al que tiene en la actualidad: "Extender, alargar y hacer mayor una cosa y que ocupe más lugar" (Diccionario de Autoridades). 
(10) mediante Dios, que encamine aquello que más nos convenga a su santo servicio dilatándome la vida de Vuestra Merced por muchos y felices años (1675, Felipe Moscoso a Duarte de Silva, p. 509)

Entre la correspondencia escrita por Felipe Moscoso, cabe destacar el ejemplo que sigue, dirigido a Antonio Manfelt. Aunque en este corpus hay un total de 12 cartas dirigidas a Manfelt, en todas las demás misivas el tono de Moscoso resulta neutro, con estructuras convencionalizadas. Sin embargo, esta carta merece especial atención por la redacción y la elaboración de la fórmula utilizada en la despedida. La sintaxis es más compleja de lo habitual, con varios gerundios y una oración de relativo, la selección léxica también es poco frecuente, además del uso de la expresión dilatar la vida, también se incluye un referente menos habitual, Divina Majestad. Todo ello sugiere una excesiva formalidad y cortesía negativa:

(11) concluyo suplicando a su Divina Majestad nos encamine lo que conduzca a su mayor gloria dilatando la vida de Vuestra Merced por muchos años como deseo, etc. (1679, Felipe Moscoso a Antonio Manfelt, p. 588)

Al examinar el contenido de la carta la sintaxis elaborada se mantiene, el autor parece tomarse la libertad de anticipar un cargamento de bienes sin haber recibido confirmación del pedido por parte del comprador. Este hecho parece poco habitual en las transacciones de Moscoso e intenta salvar su propia imagen ante esa decisión a la vez que da opciones a Manfelt por si no estuviese de acuerdo. La función comunicativa de la carta requiere que el autor no se limite a las fórmulas convencionales y enfatice su sinceridad con mayor complejidad léxica y gramatical.

En las 10 cartas que dirige Manuel Moscoso a su hermano Felipe Moscoso se incluye una formulación de despedida prácticamente idéntica, como la que se muestra en (12), lo que nos permite observar este tipo de estructuras incluso en las relaciones más próximas:

(12) Dios guarde a Vuestra Merced los muchos años que deseo y he menester (1681, Manuel Moscoso a Felipe Moscoso, p. 237)

Por tanto, la similitud en las expresiones utilizadas en este corpus entre distintos autores, incluyendo relaciones de carácter comercial o personal, es indicativa de la convencionalización de estas fórmulas en la época. Como sugiere Del Lungo Camiciotti (2008) en su estudio de cartas comerciales del siglo XIX, en este tipo de texto no abundan las estrategias de cortesía más indirectas, asociadas a una cortesía negativa, ya que los interlocutores negocian tanto actividades comerciales como mantienen una relación de carácter personal. De este modo, es más probable que los autores se ciñan a las convenciones sociales de la época y restrinjan los aspectos de cortesía a los mínimos necesarios en saludos, despedidas, peticiones de carácter comercial, etc. para que las funciones pragmáticas de la carta no se vean afectadas. 


\subsubsection{Cartas de sor María de Ágreda y del rey don Felipe IV}

La estructura general de las cartas en el subcorpus de la correspondencia entre sor María de Agreda y Felipe IV está directamente relacionada con la intención de ambos. El monarca inicia con agradecimientos a la religiosa, por lo general por sus palabras en una carta anterior y por sus oraciones; a continuación expone los eventos o situaciones que han acaecido desde su última carta con énfasis en sus preocupaciones, tales como "noticias sobre el estado de salud de su familia, los problemas en los distintos frentes de guerra, la flota, pestes, revueltas" (Baranda 1991:35) y finaliza el párrafo o párrafos de despedida con peticiones a sor María en relación con la siguiente carta y para que "apriete" ante Dios con sus oraciones. Las epístolas de la monja inician, asimismo, con referencias a la carta previa del rey y con muestras de compasión hacia la situación que atraviesa el monarca. Continúan con diferentes alusiones de carácter religioso y espiritual sobre cómo ha de entender el soberano la voluntad divina, con respuesta a sus solicitudes y con un resumen de los rezos que ha hecho la congregación en su favor. Concluye sor María con sus mejores deseos al monarca con la intervención de Dios.

Esta colección muestra una gran variedad de referencias de carácter religioso, como se muestra en la Tabla 3 y en los ejemplos (13)-(16), posiblemente debido al carácter espiritual de estas cartas.

\begin{tabular}{|l|c|c|c|}
\hline Referencias de carácter religioso & TOTAL & prosperar & guardar \\
\hline Altísimo & $\mathbf{5 7}$ & $45^{\mathrm{a}}$ & $13^{\mathrm{b}}$ \\
\hline Dios & $\mathbf{2 0}$ & $8^{\mathrm{c}}$ & $6^{\mathrm{d}}$ \\
\hline Todopoderoso & $\mathbf{1 8}$ & $8^{\mathrm{e}}$ & $5^{\mathrm{f}}$ \\
\hline Señor & $\mathbf{1 0}$ & $6^{\mathrm{g}}$ & $3^{\mathrm{h}}$ \\
\hline Dios nuestro Señor & $\mathbf{1}$ & -- & -- \\
\hline Muy Alto & $\mathbf{1}$ & 1 & -- \\
\hline Padre celestial & $\mathbf{1}$ & 1 & -- \\
\hline Poderoso & $\mathbf{1}$ & 1 & -- \\
\hline
\end{tabular}

a Diez con guardar

b Diez con prosperar

c Dos con guardar

d Dos con prosperar

e Uno con guardar

f Uno con prosperar

g Dos con guardar

h Dos con prosperar

Tabla 3. Referentes y verbos en despedidas (Corpus íntimo)

Las cartas de sor María incluyen expresiones de despedida muy variadas, de mayor creatividad y elaboración que las de otros autores, con fórmulas de cortesía más extensas, posiblemente porque se trata de una correspondencia más íntima y menos estereotipada en cuanto a estructura. 
Entre ellas encontramos desde formulaciones más escuetas como en (13) o (14), que se suelen repetir con estructuras similares, a otras con partes menos formulaicas como en (15) o (16):

(13) El Altísimo prospere ${ }^{11}$ á V.M. felices años. (1645, Sor María al rey Felipe IV, p. 32, carta XX)

(14) Guárdeme el Altísimo y prospere á V. M. (1649, Sor María al rey Felipe IV, p. 404, carta CCXXX)

(15) Quiera el Todopoderoso por su bondad que sea con próspero suçesso, mucha salud y larga vida. (1646, Sor María al rey Felipe IV, p. 102, carta LXI)

(16) y yo no cesaré de suplicar al Señor nos guarde á V.M. con felices dichas y prosperidades. (1646, Sor María al rey Felipe IV, p. 344, carta CC)

La variedad de estructuras también puede estar relacionada con el destinatario, ya que, al tratarse del rey, parece plausible que la autora quisiese enfatizar la sinceridad de sus buenos deseos elaborando las estructuras más convencionalizadas. Por el contrario, el monarca no suele hacer uso de ese tipo de expresiones en las que se solicita protección divina para el interlocutor, sino que reclama oraciones en favor propio.

En cuanto a la proporción de estructuras de despedida con referente religioso, en las misivas de sor María encontramos 100 en 120 cartas, mientras que por parte del rey Felipe IV solo 9 en 114 cartas. Por tanto, tan solo 9 de los ejemplos incluidos en la Tabla 3 se encuentran en epístolas del monarca, en las que usa como referentes Dios (8) y Señor (1). Los únicos ejemplos de las formas más convencionalizadas Dios os guarde (2) y Él os guarde (2) corresponden al Rey, como en (17), en el que también se muestra una de sus habituales solicitudes a la religiosa:

(17) Encomendadme á Dios, Sor María; El os guarde. (1648, rey Felipe IV a sor María, p. 330, carta CXCI)

Por lo que respecta a los verbos utilizados, este subcorpus difiere de los anteriores en cuanto al verbo más frecuente, ya que prosperar, con 70 casos, forma parte del mayor número de ejemplos, seguido por guardar, en 27 de ellos.

\subsubsection{Cartas incluidas en las seis primeras partes de comedias de Calderón}

El trabajo con piezas teatrales del Siglo de Oro presenta ciertas dificultades, destacando, para el estudio que aquí nos ocupa, el hecho de que no es posible concretar la fecha de redacción de los textos que manejamos, por lo que, en los ejemplos que siguen, se omitirá este dato; si bien tenemos constancia de que todas las obras incluidas en estas partes han sido redactadas entre 1623 y 1680. Asimismo, a diferencia de la mayoría de las cartas observadas en los otros corpus, las epístolas en las composiciones teatrales finalizan, cuando no lo hacen de manera abrupta, con la despedida (o esta precede tan solo la firma). No hay, entonces, por lo general, ni un primer ni un último párrafo

11 Prosperar aquí tiene el valor de “ocasionar prosperidad”. El ejemplo Dios te prospere que incluye la última edición del $D R A E$ aparece recogido ya en la edición de 1884 (s.v. prosperar). 
que indique fecha o lugar, como es lógico, por ser innecesario para el público teatral y, además de ello, debe mencionarse también la abundancia de cartas anónimas. Así pues, se trata de un corpus que presenta ciertas peculiaridades.

En lo que concierne al análisis de las despedidas de las 31 notas, avisos y cartas, en prosa, incluidas en las 72 piezas teatrales que conforman las seis primeras partes de comedias de Calderón de la Barca, es preciso volver a llamar la atención sobre el hecho de que desconocemos en numerosas ocasiones si estas comunicaciones se están reproduciendo de manera íntegra o no. Esto explica que en este subcorpus descienda el porcentaje de despedidas en comparación con las obras anteriormente analizadas. Así, hallamos que en estas 31 misivas solo disponemos de 14 fórmulas claras de despedida, todas ellas con referencia a la divinidad.

En la Tabla 4 puede observarse cuál es su distribución de acuerdo con el verbo y el referente empleado:

\begin{tabular}{|l|c|c|c|}
\hline \multirow{2}{*}{ verbos utilizados } & \multicolumn{3}{|c|}{ Referencias de carácter religioso } \\
\cline { 2 - 4 } & Dios & Júpiter & el dador de luz \\
\hline guardar & 12 & 1 & - \\
\hline amparar & - & - & 1 \\
\hline
\end{tabular}

Tabla 4. Referentes y verbos en despedidas (Corpus calderoniano)

El tipo de expresión más frecuente en el corpus calderoniano es, pues, Dios os/te guarde, que aparece en 12 ocasiones de un total de 14. Se incluyen a continuación tres ejemplos en los que la estructura Dios os guarde es utilizada como despedida de la carta:

(18) "El mayor argumento de la nobleza fue siempre la cortesía. La vuestra me asegura la verdad de todo, y así os he menester para fiar de vos un secreto. Tened una silla para luego en San Sebastián, y una casa donde pueda hablaros. Dios os guarde. - La dama muda" (Mañanas de abril y mayo, Comedias III)

(19) "El marqués de Brandemburg, mi pariente, va en servicio de Carlos a esa corte. Ya sabéis la deuda en que están los Pimenteles a Alemania, pues tantas veces les han dado en sus campañas la gloria de lo que han lucido en ellas. Como estranjero, no estará en la ceremonia castellana y así, os le encomiendo a vos, como al mejor ejemplar suyo. Dios os guarde. Maximiliano" (El postrer duelo de España, Comedias IV)

(20) "Prima y señora mía: Habiendo de vivir en tu casa, donde es preciso aumentar la familia que no habías menester en este convento, a nadie podrás recibir con más satisfacción en tu servicio que a Laura, hija de Lisardo, a quien la fortuna ha puesto en obligación de servir; y porque sé que mi ruego es la mejor autoridad para su conveniencia, te lo suplico, fiada en que, siendo él el pretendiente, has de ser tú la agradecida. Dios te guarde" (Primero soy yo, Comedias VI)

El ejemplo (18) está extraído de una carta anónima dirigida a don Hipólito y escrita por su prometida doña Clara con la intención de burlarse de él; por otro lado, la carta que se reproduce en (19) está escrita por el emperador Maximiliano al conde de Benavente, mientras que la que se ob- 
serva en (20) va dirigida a Hipólita de parte de su prima. Como se puede apreciar, las misivas que encontramos en las comedias calderonianas están escritas por hombres y mujeres entre los que se establecen relaciones de distinta índole, lo cual nos lleva a suponer que esta fórmula de despedida no varía en función del sexo de los receptores y emisores o de los rangos sociales de ambos, ya que es utilizada tanto por el emperador, el rango nobiliario más alto, como entre personajes con un vínculo familiar estrecho.

Una despedida con una mayor creatividad se encuentra en el ejemplo (21), que se explica por la intención de parodia del dramaturgo. A este respecto, señala Neumeister que “[e]l estilo épico ridiculizado de esta carta, típico del lenguaje de los libros de caballerías, es tan elevado [...] que Calderón hace comentarlo no por Doña Ángela, sino por su criada Beatriz" (2011: 279).

(21) “Fermosa dueña, cualquier que vos seáis la condolida deste afanado caballero, y assaz piadosa minoráis sus cuitas, ruégovos me queráis facer sabidor del follón mezquino o pagano malandrín que en este encanto vos amancilla, para que segunda vegada en vueso nombre, sano ya de las pasadas feridas, entre en descomunal batalla, maguer que finque en ella, que non es la vida de más pro que la muerte, tenudo a su deber un caballero. El dador de la luz vos mampare e a mí non olvide. El caballero de la Dama Duende" (La dama duende, Comedias I)

Por otro lado, llama también la atención la expresión Júpiter os guarde en el ejemplo (22), correspondiente a la obra Argenis y Poliarco, cuya trama, ambientada en la Antigüedad clásica, provoca que, en lugar de un referente explícito a un ente religioso en la tradición católica, se atribuya la función de protección en la despedida a una divinidad romana ${ }^{12}$ :

(22) "Un hombre de los muchos que tenéis obligados - porque nunca el bien se pierde- os avisa que Arsidas va a buscaros de parte del Rey, que aborrece vuestra vida y, para mataros más seguramente, Argenis os envía una banda con veneno. No os la pongáis, sino haced la experiencia: veréis qué dama amáis y qué rey servís. Júpiter os guarde”. (Argenis y Poliarco, Comedias II)

En este fragmento, Poliarco lee una carta anónima dirigida a él, enviada por el malvado bandolero Eristenes con el objetivo de sembrar dudas sobre su amada Argenis.

\section{Discusión}

En la Figura 1, a continuación, se muestran los datos de todos los corpus con una distinción de los porcentajes de uso y no uso de alguna de las distintas expresiones convencionalizadas con referentes de carácter religioso en las despedidas:

12 La acción de Argenis y Poliarco tiene lugar "en un periodo mítico que, lejos de identificarse con el presente del espectador del momento - el primer tercio del siglo XVII—, se distancia deliberadamente de esta franja temporal por medio de una serie de recursos que tienen como finalidad evocar un tiempo difuso, a medio camino entre el pasado y la leyenda [...] En este universo exótico, que agradaría a un público ansioso de fantasía, conviven de forma armoniosa [...] tímidas alusiones cristianas con múltiples referencias a la cultura grecolatina" (Vara López 2012: 444-445). 


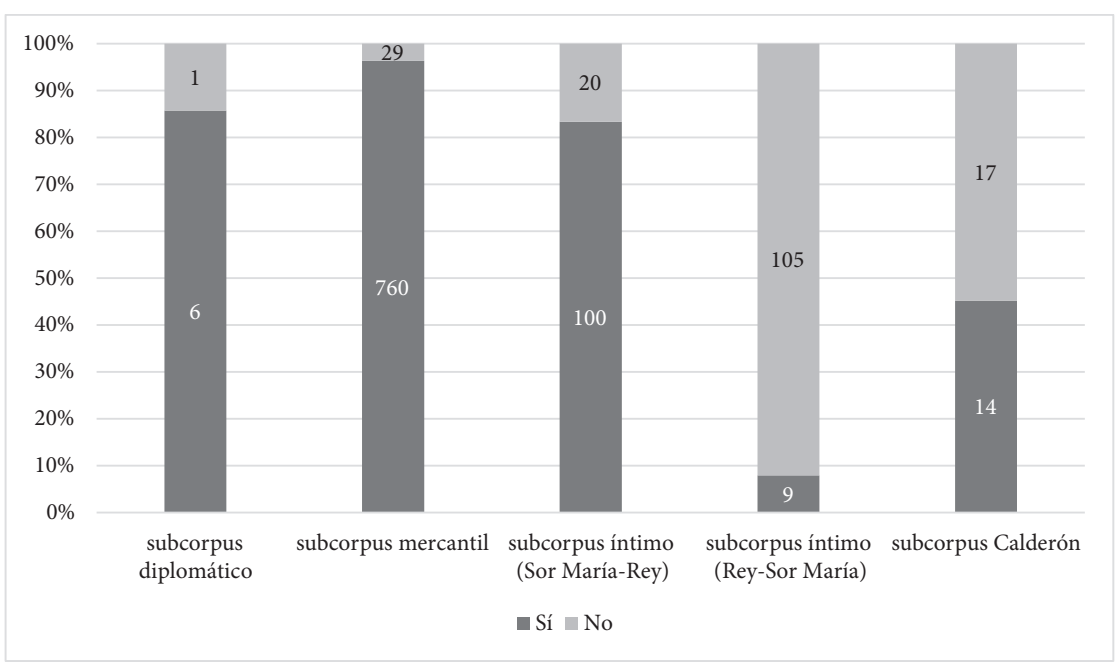

Figura 1. Presencia de estructuras formulaicas con referente religioso en despedidas

Los corpus más convencionalizados en cuanto al uso de despedidas con referente religioso son los de carácter diplomático y mercantil. Si bien el primero tan solo contiene 7 cartas y seis de ellas incluyen una de estas estructuras $(85,7 \%)$, en el segundo, mucho más numeroso, un $96,3 \%$ de las misivas sigue este patrón. Si distinguimos la correspondencia enviada por Felipe Moscoso de aquella de la que es destinatario, el uso de estas fórmulas llega hasta el $98,5 \%$ mientras que en las recibidas se mantiene en un $93,2 \%$. A pesar de la pequeña variación en los porcentajes se pone de relevancia el alto grado de convencionalización que tenían estas estructuras formulaicas.

En el corpus íntimo entre sor María de Ágreda y Felipe IV se ha decidido incluir en el gráfico las diferencias entre las muestras de cartas de la religiosa y las del rey por el gran contraste que se ofrece. Como se puede observar, sor María hace uso de despedidas con referente religioso en el 83,3\% de las epístolas que dirige al monarca, mientras que este tan solo incluye una fórmula convencionalizada con referente religioso con valor de despedida en un 7,9\% de sus misivas. El porcentaje de sor María está más próximo al de carácter mercantil, sin embargo el dato del monarca contrasta con todos los demás subcorpus y puede estar justificado principalmente por la posición social que ocupaba, pero también en buena medida por el contenido de las cartas en las que su preocupación máxima era la protección divina para sí mismo, su familia y sus territorios.

Las cartas del corpus calderoniano siguen un patrón diferente, son mayoría las que no hacen uso de una expresión de despedida con referente religioso $(54,8 \%)$ frente a las que sí la incluyen $(45,2 \%)$. Esto se explica, como ya se ha avanzado, porque en diversas ocasiones las misivas no se reproducen de manera íntegra.

En cuanto a las formas verbales que se incluyen en las estructuras formulaicas se observa que las más frecuentes contienen la idea de protección de la vida del destinatario (guardar, prosperar, dilatar la vida) y que la más frecuente en los distintos subcorpus es guardar, con excepción del corpus íntimo, en el que prosperar es utilizado en más del doble de despedidas que guardar, algo 
posiblemente asociado al uso idiosincrático de Sor María, bien por su condición de pertenencia a una comunidad religiosa o por un sesgo individual.

Algo similar ocurre con el referente seleccionado, mientras lo más frecuente en el conjunto de las colecciones parece ser Dios, seguido de Señor, destacan los usos individuales de Altísimo y Todopoderoso en la correspondencia entre sor María y Felipe IV, de nuevo posiblemente motivado por el carácter espiritual que presenta la correspondencia y por la condición religiosa de la monja.

La longitud y formulaicidad de las estructuras utilizadas como despedida tiende a variar dependiendo del grado de familiaridad entre autor y receptor. Así, aquellos con una relación más cercana tienden a usar estructuras más convencionalizadas, mientras que cuando existen relaciones socialmente asimétricas (y el remitente ocupa una posición de superioridad) o la correspondencia tiene lugar entre personas que apenas se conocen o es poco frecuente, las estructuras tienen mayor complejidad y van más allá de la formulación básica para mostrar deferencia (cf. Sánchez Roura 2002: 267 en la colección de las Cely Letters, de finales del siglo $\mathrm{XV})$. Es preciso también señalar a este respecto que el corpus calderoniano es el único en el que solo se emplea la estructura más breve, probablemente porque el público al oír esa expresión se daría cuenta de inmediato de que se ha acabado la carta, por lo que el acto de habla cumpliría así su función comunicativa, al mismo tiempo que se aporta agilidad a la escena.

La relación entre el rey Felipe IV y sor María de Ágreda parece la más asimétrica de entre las que se encuentran en la correspondencia analizada, y se observa cómo el soberano puede prescindir de las formulaciones de despedida.

Las expresiones de tipo Dios os guarde tenían el valor de despedida no solo en el lenguaje epistolar, sino también como respuesta a un saludo previo del tipo a Dios o quedad a Dios (cf. Vila y Faya 2016), de tal modo que el matiz conjunto de despedida y bendición era común al lenguaje oral y al lenguaje escrito en las estructuras formulaicas de la correspondencia, como expresión común en el acto de habla de despedidas en el Siglo de Oro.

\section{Conclusiones}

El lenguaje epistolar tiende a mostrar unas características prefijadas en su estructura y en las expresiones formulaicas que se utilizan, algo que tiene mayor importancia en épocas remotas y en situaciones en las que la carta era la principal forma de comunicación por motivos personales o profesionales. Como se puede extraer del análisis de los ejemplos mostrados, había una elevada convencionalización de las despedidas en la correspondencia del Siglo de Oro, que permitía poca variación para convenir a la norma establecida en esa sociedad. La amplia representación geográfica del material analizado nos permite determinar que las fórmulas de despedida con referente religioso estaban asentadas en todo el territorio español. Por lo observado en los distintos subcorpus, no se aprecian diferencias en la formulación de las estructuras de despedida en cartas de la primera y segunda mitad del siglo XVII, por lo que estas expresiones estaban arraigadas como parte de la cortesía normativa del lenguaje epistolar en la época.

La variedad de estructuras que se utilizaban en el Siglo de Oro en el párrafo de despedida estaban restringidas en gran medida a la alusión a un referente religioso al que se solicitaba la 
protección del destinatario. Como se ha visto, estas estructuras estaban muy convencionalizadas, incluso con respecto a los verbos que se utilizaban, en la mayoría de los casos guardar o prosperar, y a los referentes religiosos incluidos, sobre todo Dios y Señor. Ello difiere, como ya apuntábamos en el epígrafe 2 del presente artículo, de las fórmulas de despedida que parecían predominar en el habla cotidiana en el siglo XVII, pues, como se indica en Vila y Faya (2016) las expresiones más frecuentes en el diálogo eran a Dios y quédate a Dios (y variantes), apareciendo el verbo guardar solamente (y de manera ocasional) como par adyacente de las fórmulas mencionadas ${ }^{13}$.

A veces, el autor podía introducir pequeñas variaciones en estas expresiones, que en último término dependían de la relación entre remitente y destinatario y especialmente del estatus social de ambos. En ocasiones, la situación comunicativa podía requerir un grado más elevado de cortesía negativa y el remitente utilizaba una estructura de mayor elaboración para contribuir a un mayor nivel de sinceridad o deferencia. En las relaciones más simétricas se muestra un menor nivel de creatividad y los autores se limitaban a hacer uso de fórmulas más breves y convencionales que cumplían la función de cortesía normativa que exigía la situación.

Este trabajo resalta el uso de la correspondencia como fuente textual en el estudio de funciones pragmáticas por el carácter relativamente interactivo de este género y pone de relieve la importancia que adquiere la edición de material auténtico en la disciplina de la pragmática histórica en siglos pasados.

\section{Referencias bibliográficas}

Álvarez, A. I. (2005). Hablar en español: La cortesía verbal. La pronunciación estándar. Las formas de expresión oral. Oviedo: Nobel.

Arnovick, L. (1999). Diachronic Pragmatics: Seven Case Studies in English Illocutionary Development. Amsterdam / Philadelphia: John Benjamins.

Austin, J. L. (1962). How to Do Things with Words. Oxford: Clarendon Press.

Baranda Leturio, C. (1991). Introducción. In C. Baranda Leturio (Ed.), Correspondencia con Felipe IV. Religión y razón de estado (pp. 9-46), Madrid: Editorial Castalia.

Briz Gómez, A., \& Albelda Marco, M. (2010). Aspectos pragmáticos. Cortesía y atenuantes verbales en las dos orillas a través de muestras orales. In M. Aleza, \& J. M. Enguita (Coords.), La lengua española en América: normas y usos actuales (pp. 237-260), València: Universitat de València.

Calderón de la Barca, P. (2006). Comedias I. L. Iglesias Feijoo (Ed.). Madrid: Biblioteca Castro.

. (2007a). Comedias II. S. Fernández Mosquera (Ed.). Madrid: Biblioteca Castro.

(2007b). Comedias III. D. W. Cruickshank (Ed.). Madrid: Biblioteca Castro.

(2009). Comedias IV. S. Neumeister (Ed.). Madrid: Biblioteca Castro.

(2010). Comedias V. J. M. Ruano de la Haza (Ed.). Madrid: Biblioteca Castro.

(2011). Comedias VI. J. M. Viña Liste (Ed.). Madrid: Biblioteca Castro.

Canonica, E. (2015). Usos y funciones de la carta en el teatro del Siglo de Oro: elementos para una tipología. In M. C. Panzera, \& E. Canonica (Dirs.), La lettre au carrefour des genres et des traditions du Moyen Âge au XVIIe siècle (pp. 329-351). Paris: Classiques Garnier. 
Castillo Gómez, A. (2014). Cartas desde el convento. Modelos epistolares femeninos en la España de la Contrarreforma. Cuadernos de Historia Moderna. Anejos, 13, 141-168.

Culpeper, J., \& Kytö, M. (2010). Early Modern English Dialogues: Spoken Interaction as Writing. Cambridge: Cambridge University Press.

De Ágreda, M. J. (1885). Cartas de la Venerable Madre Sor María de Ágreda y del señor rey don Felipe IV. Madrid: Sucesores de Rivadeneyra.

De Gayangos, P. (1869). Cinco cartas político-literarias de don Diego Sarmiento de Acuña, primer conde de Gondomar, embajador a la corte de Inglaterra. 1623-1622. Madrid: Sociedad de Bibliófilos Españoles.

Del Lungo Camiciotti, G. (2008). Two polite speech acts from a diachronic perspective: Aspects of the realisation of requesting and undertaking commitments in the nineteenth-century commercial community. In A. H. Jucker, \& I. Taavitsainen (Eds.), Speech Acts in the History of English (pp. 115-131). Amsterdam/ Philadelphia: John Benjamins.

Fernández Amaya, L. (2010). La cortesía en español peninsular. Análisis de la secuencia de cierre en conversaciones telefónicas. In F. Orletti, \& L. Mariottini (Eds.), (Des)cortesía en español. Espacios teóricos $y$ metodológicos para su estudio (pp. 111-129). Roma-Estocolmo: Università di Roma Tre-EDICE.

Fitzmaurice, S. M. (2000). Like talking on paper? The pragmatics of courtship and the eighteenth-century familiar letter. Language Sciences, 22, 359-383.

García Macías, H. (2004). Funciones de las maldiciones y las bendiciones en La Celestina. Función, 21-24, 366-392.

Grzega, J. (2005). Adieu, bye-bye, cheerio: The ABC of leave-taking terms in English language history. Onomasiology Online, 6, 56-64.

Haverkate, H. (1994). La cortesía verbal: Estudio pragmalingüístico. Madrid: Gredos.

Jucker, A. H. (1994). The feasibility of historical pragmatics. Journal of Pragmatics, 22 (5), 533-536.

. (1998). Historical pragmatics: An interdisciplinary approach. In R. Borgmeier, H. Grabes, \& A. H. Jucker (Eds.), Anglistentag 1997. Giessen. Proceedings (pp. 3-7). Trier: Wissenschaftlicher Verlag.

- (2000). English historical pragmatics: Problems of data and methodology. In G. di Martino, \& M. Lima (Eds.), English Diachronic Pragmatics (pp. 17-55). Napoli: CUEN.

. (2011). Greetings and farewells in Chaucer's Canterbury Tales. In P. Pahta, \& A. H. Jucker (Eds.), Communicating early English manuscripts (pp. 229-240). Cambridge: Cambridge University Press.

Koch, P. (1999). Court records and cartoons: Reflections of spontaneous dialogue in early Romance texts. In A. H. Jucker, F. Lebsanft, \& G. Fritz (Eds.), Historical Dialogue Analysis (pp. 399-429). Amsterdam: John Benjamins.

Marín Cepeda, P. (2016). Amigo, hermano y señor: formulaciones de la amistad en cartas del siglo XVI. In J. Varo, \& A. Soria (Eds.), Estudios de Historia Conceptual. Siglo XVI (pp. 97-118). Granada: Universidad de Granada.

Montojo Montojo, V. (2013). Correspondencia mercantil en el siglo XVII. Las cartas del mercader Felipe Moscoso (1660-1685). Murcia: Universidad de Murcia.

Morant Marco, R. (1991). La secularización lingüística en español. Iberoromania, 33, 58-73.

Neumeister, S. (2011). Funciones y avatares de la carta en las comedias de Calderón. Anuario Calderoniano, 4, 263-281.

Palander-Collin, M. (2010). Correspondence. In A. H. Jucker, \& I. Taavitsainen (Eds.), Historical Pragmatics (pp. 651-677). Berlin/New York: Mouton de Gruyter.

Real Academia Española. (1990). Diccionario de Autoridades. Madrid: Gredos. . (1992). Diccionario de la lengua española. 21ª edición. Madrid: Espasa-Calpe.

Sánchez Roura, T. (2002). The pragmatics of captatio benevolentiae in the Cely letters. Journal of Historical Pragmatics, 3 (2), 253-272. 
Searle, J. (1979). Expression and Meaning: Studies in the Theory of Speech Acts. Cambridge: Cambridge University Press.

Slowik, M. (2009). La cortesía verbal en lenguas checa y española: Estudio pragmalingüístico contrastivo. Tesis de doctorado. Universidad Masaryk.

Vara López, A. (2012). Edición crítica y estudio literario de Argenis y Poliarco de Calderón de la Barca. Tesis de doctorado. Universidade de Santiago de Compostela.

Vila Carneiro, Z., \& Faya Cerqueiro, F. (2016). Consideraciones acerca de la fórmula de despedida a Dios en el teatro del Siglo de Oro. Onomázein, 33 (1), 39-56. 